\title{
Follicular Fluid Cortisol Releasing Hormone (CRH) Levels and Assisted Reproductive Treatment (ART) Outcomes
}

\author{
L. N. Lim¹, P. R. Supramaniam1, M. Mittal1, E. A. Linton'2, E. McVeigh ${ }^{2}$ \\ ${ }^{1}$ Oxford University Hospitals NHS Foundation Trust, John Radcliffe Hospital, Oxford, UK \\ ${ }^{2}$ Nuffield Department of Obstetrics and Gynaecology, Women's Centre, University of Oxford, John Radcliffe Hospital, Oxford, UK \\ Email: lee.lim@ouh.nhs.uk, prasannaraj@doctors.org.uk, monica.mittal@nhs.net, elizabeth.linton@obs-gyn.ox.ac.uk, \\ enda.mcveigh@obs-gyn.ox.ac.uk
}

How to cite this paper: Lim, L.N., Supramaniam, P.R., Mittal, M., Linton, E.A. and McVeigh, E. (2017) Follicular Fluid Cortisol Releasing Hormone (CRH) Levels and Assisted Reproductive Treatment (ART) Outcomes. Open Journal of Obstetrics and Gynecology, 7, 1271-1281.

https://doi.org/10.4236/ojog.2017.713130

Received: August 28, 2017

Accepted: December 17, 2017

Published: December 20, 2017

Copyright (c) 2017 by authors and Scientific Research Publishing Inc. This work is licensed under the Creative Commons Attribution International License (CC BY 4.0).

http://creativecommons.org/licenses/by/4.0/

\begin{abstract}
Purpose: Can Cortisol Releasing Hormone (CRH) levels in follicular fluid predict outcomes following assisted reproductive treatment (ART) cycles? Methods: Prospective cohort study of 50 women undergoing in vitro fertilisation (IVF)/intra-cytoplasmic sperm injection (ICSI) cycles over a two month study period. All patients were treated on the long stimulation protocol; follicular fluid was aspirated and pooled for each patient. The samples were processed appropriately and assayed using CRH radioimmunoassay (RIA). Results: This study confirmed that CRH was present in follicular fluid. The average level detected was $173 \pm 9 \mathrm{pg} / \mathrm{mL}$ (mean \pm standard error of mean [SEM]). The data suggests a positive correlation of CRH follicular fluid levels greater than $145 \mathrm{pg} / \mathrm{mL}$ with successful ART outcomes. Conclusion: The data indicates a positive correlation between ART outcomes and the presence of follicular fluid CRH levels greater than $145 \mathrm{pg} / \mathrm{mL}$. The results should be interpreted with caution due to the small sample size and pooling of follicular fluid per patient. Furthermore, the pooling of follicular fluid is not representative of $\mathrm{CRH}$ levels in an individual follicle, and thus, mature oocyte. This study serves as a reminder to what has previously been hypothesised.
\end{abstract}

\section{Keywords}

Cortisol Releasing Hormone (CRH), In Vitro Fertilization (IVF), Intra-Cytoplasmic Sperm Injection (ICSI), Follicles, Mature Oocytes

\section{Introduction}

The current quoted live birth rate in the United Kingdom (UK), following assisted 
reproductive treatment (ART) is $25 \%$ [1]. Reproductive clinicians aim to individualise treatment cycles to optimise cycle outcomes for patients. One such method is the transfer of more than one embryo per cycle attempt, subsequently increasing the multiple pregnancy risk [2].

In order to increase the current ART pregnancy rate and conform to the national drive to reduce the multiple pregnancy rate, fertility clinics are working towards improving embryo selection. Whilst most human preimplantation embryos are morphologically variable, containing both healthy and abnormal cells [3] [4], it is thought that successful implantation is associated with embryos containing only a limited proportion of cells of abnormal appearance. Good quality embryos are, in turn, thought to be associated with oocytes in which nuclear and cytoplasmic maturation during oogenesis has been appropriate [5] and this is likely to depend, at least in part, on adequate provision of nutrients and growth factors to the developing oocyte. The microenvironment of human follicles is critical for normal oocyte development, folliculogenesis and timely ovulation.

Follicular fluid provides the environment in which oocyte maturation occurs, thus affecting the oocyte's potential for fertilisation and embryonic development. Studies have shown that a variety of growth factors and cytokines could play a role in oocyte development. These include members of the transforming growth factor, EGF, IGF, activin and inhibin families which can affect ovarian function. Many of these factors have been implicated as regulators of gonadal steroid secretion, corpus luteum function, embryonic development and implantation [6] [7].

Cortisol Releasing Hormone (CRH) is present in the ovary. CRH gene expression has been found to be predominantly abundant in primary antral follicles and mature human ovarian follicles, implicating an autocrine role for ovarian $\mathrm{CRH}$ in follicular maturation [8], ovulation, luteolysis and oocyte maturation processes [9] [10]. CRH peptide has also been detected in the cytoplasm of theca and stromal cells of ovarian follicles at all stages of development, as well as in the corpora lutea of both human and rat ovaries. Kerdelhue and his colleagues have reported that human follicular fluid from women undergoing in vitro fertilisation (IVF) contained CRH [11]. Theory would suggest that low levels of CRH would be expected in mature follicles as the hormone inhibits thecal steroid production [12] which is required for oocyte maturation. However, it is unknown whether follicular fluid CRH levels reflect the peptide's inhibitory function in thecal cells, or whether $\mathrm{CRH}$ has additional positive roles, modulating oocyte growth and/or inflammatory events leading to ovulation.

We aim to investigate the role of $\mathrm{CRH}$ in oocyte quality through the measurement of peptide levels in ovarian follicular fluid and relating them to pregnancy rates. Furthermore, this study looks at the objective predictive value of follicular $\mathrm{CRH}$ in IVF outcomes. This may provide evidence that the peptide can either promote or hinder quality oocyte production. 


\section{Materials and Methods}

\subsection{Patients}

Women undergoing ART [conventional IVF or intracytoplasmic sperm injection (ICSI)] treatment at Oxford Fertility, UK were prospectively recruited, during the study period. A total of 50 women were recruited into the study and gave valid written consent. Ethical approval for the study was obtained from the Oxfordshire Clinical Research Ethics Committee, reference number CO2.211. The patients were treated with the long stimulation protocol, with pituitary desensitisation commencing in the luteal phase of the menstrual cycle using a gonadotrophin releasing hormone agonist (GnRHa) (Nafarelin; Synarel, Searle, High Wycombe, UK) intranasally, $400 \mu \mathrm{g}$ twice daily. Controlled ovarian stimulation occurred with recombinant follicle stimulating hormone (r-FSH) (Gonal F, East Sussex, UK; Puregon, Organon, Cambridge, UK) which was commenced once pituitary desensitisation was confirmed by oestradiol levels less than $73 \mathrm{pmol} / \mathrm{L}$. The initial dosage of r-FSH ranged between 150 - 375 IU, dependent on the age of the female patient, early follicular phase FSH level and her body mass index. Transvaginal ultrasound scans and serum oestradiol levels were performed on three or four occasions to monitor follicular growth. When at least 3 follicles greater than $18 \mathrm{~mm}$ were present, $5000 \mathrm{IU}$ or $10000 \mathrm{IU}$ of human chorionic gonadotrophin (hCG) (Profasi; Serono, Welwyn Garden City, UK) was administered as a single injection to induce final oocyte maturation. Transvaginal ultrasound-guided oocyte retrieval was performed under sedation $35 \mathrm{hrs}$ after hCG administration. Embryo transfers (ETs) were performed 48 hrs following oocyte retrieval. Progestogen pessaries (Cyclogest, Hoechst, Hounslow, UK) were given for luteal phase support, commencing the day after oocyte retrieval. The pessary was continued for 2 weeks, when a urinary pregnancy test was undertaken to confirm pregnancy.

\subsection{Sample Collection}

The first follicular aspirates (prior to flushing of the follicle with media), for each patient was collected. The average number of follicles recruited per patient was $12.44 \pm 1.04$ (mean \pm standard error of mean $[\mathrm{SEM}]$ ). The aspirate from individual patients was pooled and the pooled sample was then centrifuged immediately at $300 \times \mathrm{g}$ for $10 \mathrm{mins}$ at $4^{\circ} \mathrm{C}$. The supernatant was collected and stored at $-20^{\circ} \mathrm{C}$, awaiting peptide extraction.

\subsection{Follicular Fluid Extraction}

The follicular fluid CRH was first extracted with methanol prior to measurement by CRH radioimmunoassay (RIA), secondary to the presence of Corticotrophin Releasing Hormone Binding Protein (CRHBP) in human follicular fluid [8] interfering with CRH estimation [13]. The samples were treated with 3 volumes of ice-cold methanol, vortexed and left to stand for $10 \mathrm{mins}$ on ice. The tubes were then centrifuged for 15 mins at $2000 \times$ g; the supernatants were transferred to 
fresh tubes and dried under a stream of nitrogen at $40^{\circ} \mathrm{C}$. Dried samples were then stored at $-20^{\circ} \mathrm{C}$ until the assay. Follicular fluid extracts were reconstituted to their original volume with assay buffer and assayed by CRH RIA.

\section{4. $\mathrm{CRH}_{1-41}$ Antibody}

The $\mathrm{CRH}_{1-41}$ antibody used had been developed within the same laboratory as part of an earlier study. Rabbit anti- $\mathrm{CRH}_{1-41}$ (code M2) was raised against synthetic human $\mathrm{CRH}_{1-41}$ coupled to bovine thyroglobulin using glutaraldehyde [13].

\subsection{Iodination of $\mathrm{CRH}_{1-41}$}

Synthetic $\mathrm{CRH}_{1-41}$ peptide was iodinated using a modification of the iodogen method of [14]: the mixture containing $5 \mu \mathrm{g}$ of synthetic $\mathrm{CRH}_{1-41}$ peptide in 20 $\mu \mathrm{L}$ of $0.2 \mathrm{M}$ sodium bicarbonate buffer $\mathrm{pH} 8.4$ and $500 \mu \mathrm{Ci}(5 \mu \mathrm{L}) \mathrm{Na}^{125} \mathrm{I}$ (Amersham, Buckinghamshire, UK) was allowed to react in a vial previously coated with $1 \mu$ g iodogen $(1,3,4,6$, tetrachloro- $3 \alpha, 6 \alpha$-diphenylglycoluril; Pierce and Warinner, Cheshire, UK) for 30 mins at room temperature. The reaction was terminated by the addition of $900 \mu \mathrm{L}$ aqueous solution of $0.1 \%$ trifluoroacetic acid (TFA). The labelled peptide was separated from the other reactants by applying it to a C4 column (Macherey-Nagel, Germany) and washing with $0.1 \%$ TFA to remove unincorporated iodine. The iodinated peptide was eluted using $10 \%$ stepwise increases in methanol concentration containing $0.1 \% \mathrm{TFA} ; 250 \mu \mathrm{L}$ of assay buffer (PBS, $0.2 \%$ BSA, $0.01 \%$ sodium azide) was added to the fraction containing the labelled peptide as shown in Table 1 which was stored at $-20^{\circ} \mathrm{C}$ until use.

To identify the optimum method of recovery of CRH in the follicular fluid, $1000 \mathrm{pg}$ of neat CRH was spiked into the follicular fluid and subjected to three different groups: 1) methanol extraction; 2) C18 Sep Pak extraction; and 3) no extraction before CRH RIA. As shown in Table 1, methanol extraction is the most efficient method for CRH extraction from the follicular fluid; therefore, it was used to extract the entire follicular fluid samples in this study.

\section{6. $\mathrm{CRH}_{1-41}$ RIA Protocol}

A 10-point standard curve, covering the range $10 \mathrm{pg} / \mathrm{mL}$ to $10 \mathrm{ng} / \mathrm{mL}$, was prepared.

Table 1. The recovery of CRH in methanol, C18 Sep Pak and non extracted follicular fluid samples.

\begin{tabular}{lccc}
\hline & Methanol $(\mathrm{pg} / \mathrm{ml})$ & C18 Sep Pak $(\mathrm{pg} / \mathrm{ml})$ & Non-Extraction $(\mathrm{pg} / \mathrm{ml})$ \\
\hline Sample 1 & 1357 & 822 & 1061 \\
Sample 2 & 1458 & 769 & 865 \\
Sample 3 & 1262 & 782 & 772 \\
Sample 4 & 1260 & 649 & 811 \\
Sample 5 & 1195 & 663 & 713 \\
Sample 6 & 1112 & 829 & 1169 \\
\hline
\end{tabular}


$50 \mu \mathrm{L}$ of M2 antibody at $1 / 3000$ dilution was added to duplicate $200 \mu \mathrm{L}$ aliquots of standard or sample and allowed to equilibrate for $24 \mathrm{hrs}$ prior to the addition of $50 \mu \mathrm{L}$ of ${ }^{125}$ I-labelled $\mathrm{CRH}_{1-41}$ [15,000 - 22,000 count per million (c.p.m.)/tube]. The reaction was held at $4^{\circ} \mathrm{C}$ overnight followed by separation by addition of 200 $\mu \mathrm{L}$ of a 1/10 dilution of sheep antiserum against rabbit Fc region (Igi Ltd, Sunderland) containing $1 \%$ normal rabbit serum (NRS: Gibco BRL, Life Technologies, Paisley, UK) and 4\% PEG 6000 (Fison, Manchester, UK) in assay buffer. The tubes were incubated at room temperature for 30 mins, after which $1 \mathrm{~mL} \mathrm{PBS/0.01 \%}$ Triton X-100 was added and the tubes were centrifuged at $4000 \times \mathrm{g}$ for $30 \mathrm{mins}$ at $4^{\circ} \mathrm{C}$. The supernatants were aspirated and radioactivity in the pellets was measured in a LKB CompuGamma counter. Dilution of standards, samples, antiserum and labelled peptide were carried out in the assay buffer.

\subsection{Embryo Grading}

The embryo quality was assessed immediately prior to embryo transfer (ET), 42 hrs after insemination. The embryo grading system ranged from A to E, with grade A being the best in terms of nucleoli, fragmentation and cell division (Figure 1): Grade A-regular or only slightly irregular blastomeres, with or without minor fragments; Grade B-irregular blastomeres, with or without minor fragments; Grade C-irregular or regular blastomeres, up to $30 \%$ fragments; Grade D-irregular or regular blastomeres, more than $30 \%$ fragments and fragmented (usually unsuitable for transfer).

\section{Results}

The mean age of the recruited female patients was 34.10 (range $22-43$ ) years. The aetiology of their infertility included male factor infertility, tubal disease, unexplained infertility, endometriosis and polycystic ovarian syndrome $(48 \%$, $24 \%, 16 \%, 10 \%$ and $2 \%$, respectively). Eighty percent of the patients had an early follicular phase (defined as day $2-5$ of menstrual cycle) FSH that was $\leq 10 \mathrm{IU} / \mathrm{L}$.

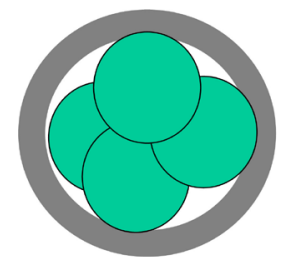

Grade A

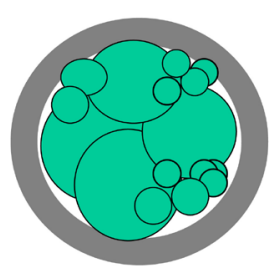

Grade D

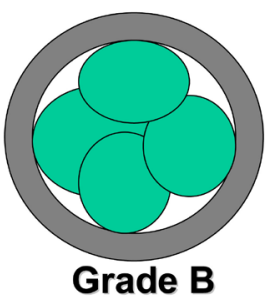

Grade B
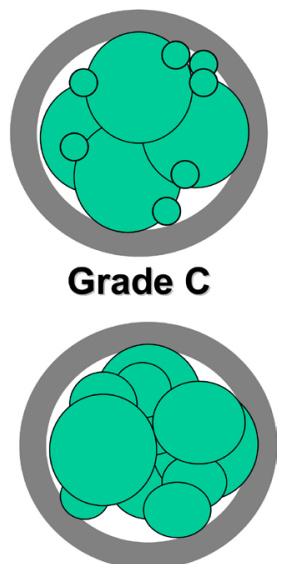

Fragmented

Figure 1. Cleavage stage embryo grading. Courtesy of Dr K. Turner, consultant embryologist, Oxford Fertility Unit, Oxford. 
Sixty-two percent of the patients (62\%) had no previous reported pregnancy. The demographics are shown in Table 2.

The mean \pm SEM oestradiol level on the day of hCG administration was 4238.30 $\pm 310.56 \mathrm{pmol} / \mathrm{L}$. The mean number \pm SEM of follicles recruited, number of oocytes retrieved and number of oocytes fertilised were $12.44 \pm 1.04,8.28 \pm 0.64$ and $5.32 \pm 0.45$, respectively (Table 3 ).

Three patients did not have an ET. Of these, two patients had failed fertilisation, whilst one patient became acutely unwell after oocyte retrieval leading to all of her embryos being frozen. With the exception of 2 patients who underwent a blastocyst stage ET, 5 days after oocyte collection, the remaining 45 patients underwent a day 2 or $3 \mathrm{ET}$. The mean number of embryos transferred per patient was $1.93(87 / 45)$. The grading of these is shown in Table 4.

In total, 12 patients had a positive pregnancy test. The pregnancy rate per Table 2. Demographics.

\begin{tabular}{ccc}
\hline & N & Percentage (\%) \\
\hline Aetiology for infertility & & 48 \\
Male factor & 24 & 24 \\
Tubal factor & 12 & 16 \\
Unexplained & 8 & 10 \\
Endometriosis & 5 & 2 \\
Polycystic ovarian syndrome & 1 & \\
Early follicular phase FSH level (IU/L) & & 10 \\
$<5$ & 5 & 70 \\
5 - 10 & 35 & 16 \\
10.1 - 15 & 8 & 4 \\
$>15$ & 2 & \\
Parity & & 62 \\
Never pregnant & 31 & 20 \\
Previous live birth & 10 & 16 \\
Previous miscarriage/ectopic & 8 & 2 \\
Previous stillbirth & 1 & \\
\hline
\end{tabular}

$p<0.05$ is considered significant.

Table 3. Patient characteristics.

\begin{tabular}{ccccc}
\hline & $\begin{array}{c}\text { Oestradiol level } \\
(\mathrm{pmol} / \mathrm{L})\end{array}$ & $\begin{array}{c}\text { No. of follicles } \\
\text { recruited }\end{array}$ & $\begin{array}{c}\text { No. of oocytes } \\
\text { retrieved }\end{array}$ & $\begin{array}{c}\text { No. of oocytes } \\
\text { fertilised }\end{array}$ \\
\hline Mean & 4238.30 & 12.44 & 8.28 & 5.32 \\
SEM & 310.56 & 1.04 & 0.64 & 13 \\
Range & 10,741 & 33 & 19 & 0.45 \\
Min - $\max$ & $804-11,545$ & $3-36$ & $1-20$ & $0-13$ \\
\hline
\end{tabular}


Table 4. Embryo grading.

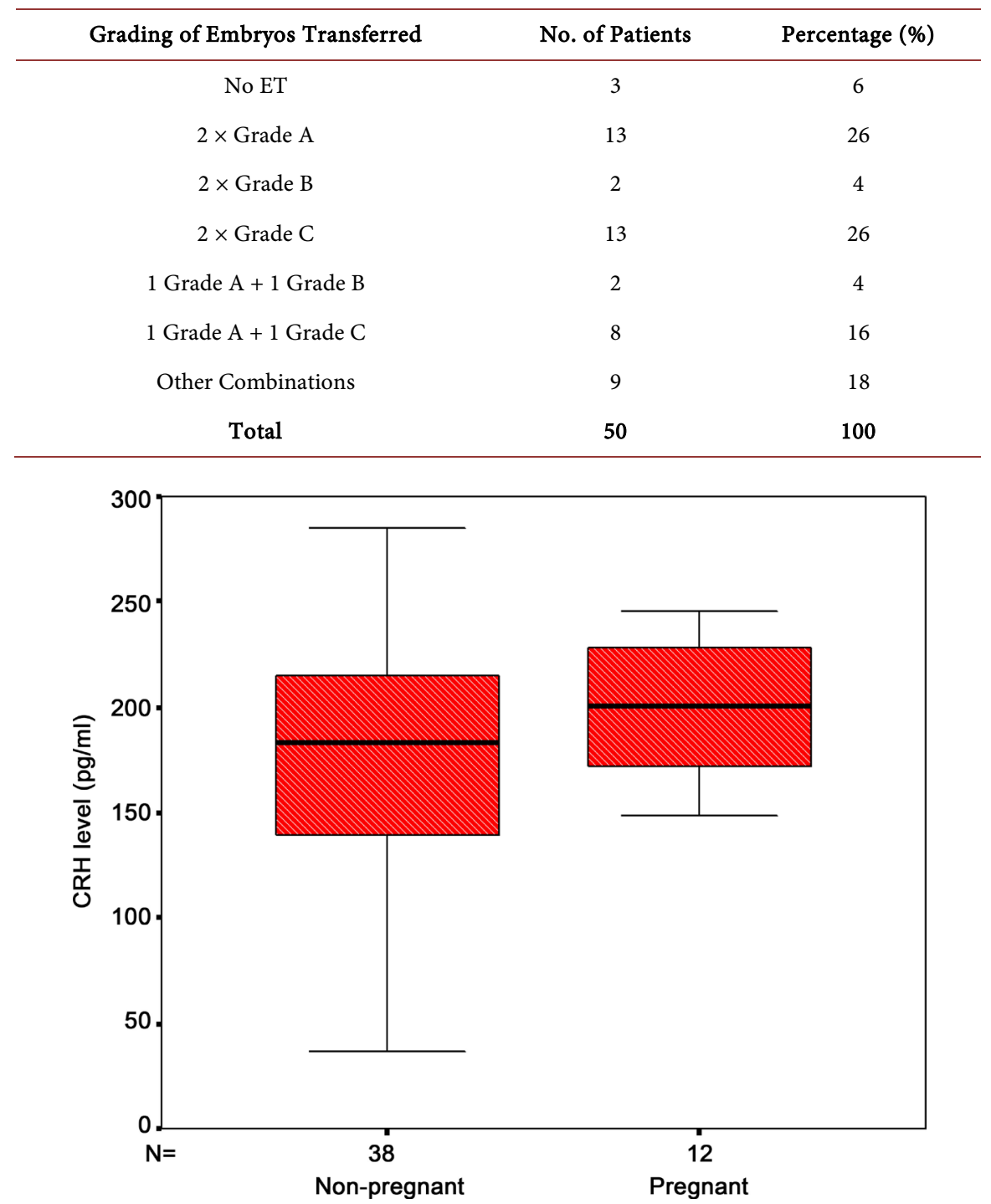

Figure 2. Ovarian follicular fluid CRH levels.

stimulated cycle was $24 \%(12 / 50)$ and the pregnancy rate per ET was $25.5 \%(12 / 47)$. Three of the 12 (25\%) pregnancies ended as first trimester losses, whilst the other 9 patients had an uneventful singleton live birth. Thus, the live birth rate per stimulated cycle was $18 \%(9 / 50)$.

This study confirmed the presence of $\mathrm{CRH}$ in follicular fluid. The average level detected was $173 \pm 9 \mathrm{pg} / \mathrm{mL}$ (mean \pm SEM). Figure 2 demonstrates the distribution of the CRH levels in the pregnant and non-pregnant groups. In this study, Pearson Correlation (where correlation is significant at the 0.05 level) indicated no link between the CRH concentration and aetiology of infertility or other recognisable favourable factors for IVF treatment, such as age of the female patients, aetiology of infertility, FSH level, parity, oestradiol level, number of follicles recruited, number of oocytes retrieved/fertilised and ET grading (Table 5). 
Table 5. Correlation of concentration of CRH with age, parity, FSH level, aetiology of infertility, level of oestradiol, number of follicles recruited, number of oocytes retrieved, number of fertilised embryos and grading of transferred embryos.

\begin{tabular}{ccc}
\hline & Pearson Correlation & Significance (2-tailed) \\
\hline Age & -0.062 & 0.670 \\
Parity & 0.013 & 0.929 \\
FSH level & 0.007 & 0.961 \\
Aetiology of infertility & -0.032 & 0.825 \\
Level of oestradiol & 0.125 & 0.386 \\
No of follicles recruited & 0.047 & 0.744 \\
No of oocytes retrieved & 0.079 & 0.588 \\
No of fertilised embryos & 0.097 & 0.503 \\
Grading of transferred embryos & 0.128 & 0.374 \\
\hline
\end{tabular}

Significant at or above the 0.05 level

\section{Discussion}

This study has demonstrated the presence of immunoreactive CRH in methanol extracted, stimulated ovarian follicular fluid, with a range of $20-285 \mathrm{pg} / \mathrm{mL}$. These levels are almost 20 fold higher than those reported by Kerdelhue and his colleagues $(5-15 \mathrm{pg} / \mathrm{mL})$ in which the peptide was extracted from follicular fluid using Sep-Pak C18 [11]. Mastorakos and his colleagues have also reported immunoreactive $\mathrm{CRH}$ in ovarian follicular fluid, obtaining $\mathrm{CRH}$ levels between 3.2 - $6.7 \mathrm{pmol} / \mathrm{L}$ (equivalent to $16-33.5 \mathrm{pg} / \mathrm{mL}$ ) using acid extraction followed by high pressure liquid chromatography after reconstitution [10]. The differences in CRH levels found could be secondary to patient variation, the heterogeneity between the methods employed for sample extraction in each study, and to the particular RIA used for measurement. It is possible, for example, that the extraction methods used in the previous two studies did not separate all of the $\mathrm{CRH}$ from any binding protein present in the sample; in these circumstances, the $\mathrm{CRH}$ measurements obtained would underestimate the true levels present in follicular fluid. Methanol extraction, on the other hand, is known to extract CRH from body fluids with efficiency approaching $100 \%$ [15]. It is also possible that the $\mathrm{CRH}$ antibodies used in the three different RIA have differing cross-reactivities to the various molecular species of $\mathrm{CRH}$, for example the $\mathrm{CRH}$ precursor, proCRH, and its intermediate metabolite, $\mathrm{CRH}_{125-194}$. The $\mathrm{CRH}$ antibody used in the present study has been shown to detect both of these CRH species in addition to the 1 - 41 peptide [16], but cross-reactivity of the other CRH antibodies with these larger molecular forms is not reported. Additional chromatographic studies would have to be performed to determine the molecular size of the immunoreactive CRH detected in follicular fluid samples.

The human follicular fluid CRH could be derived from several sources. Firstly, it might originate from the theca cells by diffusing through the granulose layer into the follicular antrum. Secondly, it may be derived from the stromal cells of 
the mature follicle, as described by Asakura and colleagues [8].

No correlation was found between follicular fluid CRH and serum oestradiol levels measured in this study. This differs from previous findings, where CRH suppressed the release of oestrogen (and insulin-like growth factor-I) from primary cultures of rat granulosa cells [17] and was able to inhibit the IL-1 mediated production of oestrogen and progesterone using granulose-theca cells from women undergoing IVF treatment [12]

This study suggests a positive correlation between successful IVF outcomes and follicular fluid levels of CRH greater than $145 \mathrm{pg} / \mathrm{mL}$. This finding is unexpected secondary to known knowledge that the hormone inhibits thecal steroid production [12] which is required for oocyte maturation. This would imply that low CRH concentrations would be expected in mature follicles. However, no direct relationship was found between the level of CRH and the pregnancy outcome following IVF treatment, which may be expected if follicular fluid CRH is beneficial rather than inhibitory (through its effect on steroid production). Furthermore, the CRH measurement could not be used as an additional objective biochemical marker for embryo selection/grading.

The conclusions may be limited by the small sample size of the study, or the experimental design adopted, with all follicular fluid aspirates from each patient being pooled to provide a mean value per $\mathrm{mL}$ per patient. $\mathrm{CRH}$ concentrations from individual follicular fluid aspirates would provide an absolute value per follicle, with a greater correlation to the oocyte from each follicle in relation to the fertilisation rate and embryo grading over pregnancy outcome. This method would account for co-variables known to impact pregnancy outcome, such as female age, parity, number of years of infertility and aetiology of infertility.

\section{Conclusion}

In summary, the study indicates a positive ART outcome with follicular fluid CRH levels greater than $145 \mathrm{pg} / \mathrm{mL}$. However, the limited study design precludes the use of follicular CRH as an objective predictor for IVF outcomes. This positive effect may be secondary to CRH's potential roles in follicular [8] and oocyte maturation [18], leading to improved oocyte quality and consequently, a higher pregnancy rate.

\section{Acknowledgements}

Nuffield Department of Obstetrics and Gynaecology for the use of their laboratories to undertake the proposed experimental work. Oxford Fertility, for access to patients and recruitment.

\section{Author's Roles}

LNL recruited the subjects, undertook the laboratory work and wrote the manuscript. PRS and MM were involved in the development of the manuscript. EAL was involved in the study design. EAL and EM oversaw the study and approved 
the final manuscript.

\section{Funding}

Funded by Organon Ltd.

\section{Conflict of Interest}

The authors report no conflicts of interest to declare.

\section{Trial Registration Number}

Ethical approval for the study was obtained from the Oxfordshire Clinical Research Ethics Committee, reference number CO2.211.

\section{References}

[1] HFEA (2014) Fertility Treatment 2014: Trends and Figures. HFEA, London.

[2] Templeton, A. and Morris, J.K. (1998) Reducing the Risk of Multiple Births by Transfer of Two Embryos after In Vitro Fertilization. New England Journal of Medicine, 339, 573-577. https://doi.org/10.1056/NEJM199808273390901

[3] Hardy, K., Winston, R.M. and Handyside, A.H. (1993) Binucleate Blastomeres in Preimplantation Human Embryos in Vitro: Failure of Cytokinesis during Early Cleavage. Journal of Reproduction \& Infertility, 98, 549-558. https://doi.org/10.1530/jrf.0.0980549

[4] Ruangvutilert, P., Delhanty, J.D., Serhal, P., Simopoulou, M., Rodeck, C.H. and Harper, J.C. (2000) FISH Analysis on Day 5 Post-Insemination of Human Arrested and Blastocyst Stage Embryos. Prenatal Diagnosis, 20, 552-560. https://doi.org/10.1002/1097-0223(200007)20:7<552::AID-PD871>3.0.CO;2-F

[5] Moor, R.M., Dai, Y., Lee, C. and Fulka Jr., J. (1998) Oocyte Maturation and Embryonic Failure. Human Reproduction Update, 4, 223-236. https://doi.org/10.1093/humupd/4.3.223

[6] Adashi, E.Y. (1994) Growth Factors and Ovarian Function: The IGF-I Paradigm. Hormone Research, 42, 44-48. https://doi.org/10.1159/000184144

[7] Murray, A. and Spears, N., Eds. (2005) What Makes a Good Egg? Implantation and Early Development. RCOG Press, London.

[8] Asakura, H., Zwain, I.H. and Yen, S.S. (1997) Expression of Genes Encoding Corticotropin-Releasing Factor (CRF), Type 1 CRF Receptor, and CRF-Binding Protein and Localization of the Gene Products in the Human Ovary. Journal of Clinical Endocrinology \& Metabolism, 82, 2720-2725.

[9] Mastorakos, G., Webster, E.L., Friedman, T.C. and Chrousos, G.P. (1993) Immunoreactive Corticotropin-Releasing Hormone and Its Binding Sites in the Rat Ovary. Journal of Clinical Investigation, 92, 961-968. https://doi.org/10.1172/JCI116672

[10] Mastorakos, G., Scopa, C.D., Vryonidou, A., Friedman, T.C., Kattis, D., Phenekos, C., Merino, M.J. and Chrousos, G.P. (1994) Presence of Immunoreactive Corticotropin-Releasing Hormone in Normal and Polycystic Human Ovaries. Journal of Clinical Endocrinology \& Metabolism, 79, 1191-1197.

[11] Kerdelhue, B., Lenoir, V., Kolm, P., Seltman, H.J., Jones, H.W. and Jones, G.S. (1997) ACTH, Beta-Endorphin, Substance P, and Corticotrophin Releasing Hor- 
mone in Plasma and Follicular Fluid in Hormonally Stimulated Menstrual Cycles for in Vitro Fertilization in the Human. Human Reproduction, 12, 231-235. https://doi.org/10.1093/humrep/12.2.231

[12] Ghizzoni, L., Mastorakos, G., Vottero, A., Barreca, A., Furlini, M., Cesarone, A., Ferrari, B., Chrousos, G.P. and Bernasconi, S. (1997) Corticotropin-Releasing Hormone $(\mathrm{CRH})$ Inhibits Steroid Biosynthesis by Cultured Human Granulosa-Lutein Cells in a CRH and Interleukin-1 Receptor-Mediated Fashion. Endocrinology, 138, 4806-4811. https://doi.org/10.1210/endo.138.11.5474

[13] Linton, E.A., Perkins, A.V., Hagan, P., Poole, S., Bristow, A.F., Tilders, F., Corder, R. and Wolfe, C.D. (1995) Corticotrophin-Releasing Hormone (CRH)-Binding Protein Interference with $\mathrm{CRH}$ Antibody Binding: Implications for Direct $\mathrm{CRH}$ Immunoassay. Journal of Endocrinology, 146, 45-53.

https://doi.org/10.1677/joe.0.1460045

[14] Salacinski, P.R.P., McLean, C., Sykes, J.E.C., Clement-Jones, V.V. and Lowry, P.J. (1981) Iodination of Proteins, Glycoproteins, and Peptides using a Solid-Phase Oxidizing Agent, 1,3,4,6-tetrachloro-3 $\alpha, 6 \alpha$-diphenyl Glycoluril (Iodogen). Analytical Biochemistry, 117, 136-146. https://doi.org/10.1016/0003-2697(81)90703-X

[15] Linton, E.A., Behan, D.P., Saphier, P.W. and Lowry, P.J. (1990) Corticotropin-Releasing Hormone (CRH)-Binding Protein: Reduction in the Adrenocorticotropin-Releasing Activity of Placental But Not Hypothalamic CRH. The Journal of Clinical Endocrinology \& Metabolism, 70, 1574-1580.

https://doi.org/10.1210/jcem-70-6-1574

[16] Ahmed, I., Glynn, B.P., Perkins, A.V., Castro, M.G., Rowe, J., Morrison, E. and Linton, E.A. (2000) Processing of Procorticotropin-Releasing Hormone (pro-CRH): Molecular Forms of CRH in Normal and Preeclamptic Pregnancy. The Journal of Clinical Endocrinology \& Metabolism, 85, 755-764. https://doi.org/10.1210/jc.85.2.755

[17] Calogero, A.E., Barreca, A., Burrello, N., Palermo, I., Giordano, G., D’Agata, R. and Vicari, E. (2002) Corticotrophin-Releasing Hormone Inhibits Insulin-Like Growth Factor-I Release from Primary Cultures of Rat Granulosa Cells. Journal of Endocrinology, 174, 493-498. https://doi.org/10.1677/joe.0.1740493

[18] Karalis, K., Sano, H., Redwine, J., Listwak, S., Wilder, R.L. and Chrousos, G.P. (1991) Autocrine or Paracrine Inflammatory Actions of Corticotropin-Releasing Hormone in Vivo. Science, 254, 421-423. https://doi.org/10.1126/science.1925600 